\title{
Formulasi Analitis Tetapan Propagasi Efektif Modus TE untuk Directional Coupler Linier Diturunkan dengan Metode Matrik Karakteristik Lapis Jamak
}

\author{
Ali Yunus Rohedi, Gatut Yudoyono, Suryadi,* dan Agus Rubiyanto \\ Jurusan Fisika, FMIPA, Institut Teknologi Sepuluh Nopember, Kampus ITS Sukolilo, Surabaya 60111
}

\begin{abstract}
Intisari
Parameter terpenting untuk menentukan panjang kopling dan formula propagasi medan directional coupler adalah nilai tetapan propagasi efektif medan moda simetri dan moda asimetri. Pada makalah ini dilaporkan formulasi tetapan propagasi efektif dimaksud untuk cahaya modus TE (transverse electric) yang terpandu dalam directional coupler linier dalam bentuk analitis. Formulasi analitis diturunkan dengan menggunakan metode matrik karakteristik pandu gelombang berlapis jamak, dan berlaku untuk kedua moda simetri dan asimetri, baik untuk struktur directional coupler simetri maupun asimetri.
\end{abstract}

KATA KUNCI: directional coupler linier, perpindahan daya, transverse electric, moda terkopel, moda-moda normal, medan evanescent

\section{PENDAHULUAN}

Pada bidang optika terpadu (integrated optics), directional coupler merupakan komponen kunci dalam pembuatan rangkaian optika terpadu. Hal ini karena kanal-kanal rangkaian optika terpadu dibuat membentuk struktur directionalcoupler. Struktur directional-coupler yang paling sederhana adallah tersusun atas dua buah pandu gelombang kanal sejajar yang ditumbuhkan pada satu substrat, dengan jarak pisah (lebar gap) beberapa panjang gelombang optik. Fungsi utama directional-coupler adalah sebagai devais pemindah daya optik, yang kinerjanya didasarkan antara lain pada kegayutan indeks bias efektifnya terhadap frekuensi, medan optik, dan atau medan luar. Indeks bias efektif dimaksud adalah nilai indeks bias dari seluruh kombinasi indeks bias bahan-bahan directional-coupler yang "dirasakan" oleh setiap moda gelombang.

Pada directional-coupler linier yang dibuat dari bahanbahan optik linier, perpindahan dayanya didasarkan pada kegayutan indeks bias efektif terhadap frekuensi dan kelinierannya terhadap penerapan medan luar, sehingga devais ini disamping dapat beroperasi secara pasif tanpa penerapan medan luar, juga dapat dioperasikan secara aktif melalui kendali tegangan. Sedangkan pada directional-coupler tak linier, indeks bias efektifnya gayut secara tak linier terhadap medan optik, dan untuk yang terbuat dari bahan-bahan optik mirip Kerr (Kerr-like) perpindahan dayanya dapat diatur melalui intensitas cahaya masukan. Directional-coupler linier lazim digunakan pada sistem komunikasi optik[1], antara lain sebagai saklar optik[2], modulator[3], polarisator[4], dan WDM[5]. Sedangkan directional-coupler tak linier disamping digunakan pada pengoperasian sistem komunikasi optik

*E-MAIL: hikari@physics.its.ac.id secara optik seluruhnya[6, 7] (All Optical Switching), juga difungsikan sebagai gerbang logika optik (NOT, AND, NAND, OR, NOR) yang merupakan komponen utama dalam pembuatan komputer optis.

Besaran yang sangat penting untuk mendesain directionalcoupler adalah nilai tetapan propagasi efektif $\beta$ dari medan optik yang akan ditransmisikannya. Nilai eigen persamaan Helmholtz untuk directional coupler tersebut, disamping diperlukan untuk memperkirakan panjang kopling yaitu jarak pemindahan seluruh daya antar pandu gelombangnya, juga sebagai besaran utama dalam formula propagasi medan yang berguna untuk memvisualisasi dan mensimulasikan berbagai macam fungsinya. Persamaan nilai eigen untuk directionalcoupler linier yang indeks bias pandu gelombangnya homogen, umumnya diturunkan menggunakan metode matrik karakteristik berlapis jamak. Hal ini karena metode matrik karakteristik berlapis jamak disamping dapat menampilkan formulasi nilai eigen dalam bentuk analitis, juga memberikan nilai perhitungan tetapan propagasi efektif yang eksak $[8,9]$. Kogelnik[8] memformulasikan dua persamaan nilai eigen analitis untuk directional-coupler linier simetri (indeks bias dan ukuran kedua pandu gelombangnya tepat sama) masingmasing untuk moda genap dan moda ganjil untuk cahaya modus TE (transverse elekctric). Perumusan dilakukan dengan memanfaatkan kesimetrian struktur, dan menetapkan pusat (center) lebar gap directional-coupl sebagai pusat koordinat.

Pada makalah ini, penerapan metode matrik karakteristik lapis jamak diupayakan untuk menghasilkan sebuah persamaan nilai eigen directional-coupler linier modus TE, yang disamping berlaku untuk struktur asimetri (indeks bias dan ukuran kedua pandu gelombangnya tidak sama) juga berlaku semua ragam moda. 


\section{TINJAUAN PUSTAKA}

Struktur directional coupler berisi dua pandu gelombang kanal ditunjukkan dalam Gambar 1. Proses pemindahan daya optik di dalam directional coupler linier secara tradisi dijelaskan dengan teori moda terkopel[10,11] dengan didasarkan pada interaksi antar medan-medan evanescent dari masingmasing pandu gelombang. Sedangkan panjang koplingnya ditentukan dari kuat kopling yaitu kuantitas saling tumpangtindih (overlapping) antara medan di kanal satu dengan medan evanescent dari kanal dua. Secara kualitatif penjelasan teori moda terkopel ini telah sesuai dengan fakta eksperimen, namun secara kuantitatif, untuk directional-coupler yang lebar gapnya relatif kecil, panjang kopling dan porsi daya optik yang dipindahkannya masih jauh dari akurat.

Metode pendekatan yang secara kuantitatif relatif lebih akurat dalam menjelaskan proses pemindahan daya optik dalam directional coupler linier adalah pendekatan modamoda normal[12, 13]. Menurut pendekatan ini, proses perpindahan daya optik terlaksana sebagai konsekuensi dari interferensi antar dua medan optik orde moda terendah yang disebut moda simetri dan moda asimetri, yang terpandu di sepanjang penampang transversalnya. Sedangkan panjang koplingnya ditentukan melalui $L_{c}=\pi /\left(\beta_{0}-\beta_{1}\right)$, dengan $\beta_{0}$ dan $\beta_{1}$ masing-masing adalah nilai tetapan propagasi efektif moda simetri dan moda asimetri. Adapun ekspresi medan kedua moda yang diperlukan dalam perhitungan tetapan propagasi efektifnya adalah medan-medan yang berlaku untuk seluruh struktur directional-coupler, bukan ekspresi medan dari masing-masing pandu gelombangnya sebagaimana yang direkomendasikan oleh teori moda terkopel. Namun demikian reduksi dimensi penampang transversal pandu gelombangnya dari dimensi dua ke dimensi satu sama-sama dilakukan dengan metode indeks efektif[13, 14]. Salah satu pendekatan normal yang sangat akurat dalam menyelesaikan persamaan Helmholtz adalah metode matrik karakteristik pandu gelombang berlapis jamak. Metode ini mulai dikenal luas pemakaiannya seiring dengan berkembangnya teknologi pelapisan

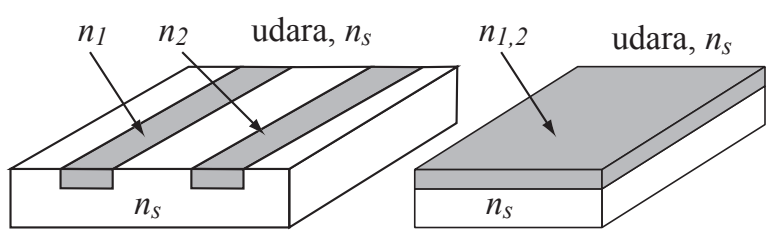

(a)

(b)

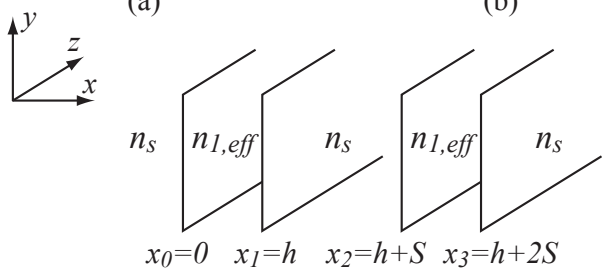

(c)

Gambar 1: Struktur Geometri Directional-coupler tipis ini, disamping lazim digunakan dalam perancangan berbagai devais fotonik, sering dipakai pula pada perancangan cermin pembalik fasa[15], monokromator dan filter[16], kavitas laser semikonduktor[17], bahkan pada persoalan interaksi polariton-exciton[18, 19] dalam mikrokaviti.

Implementasi metode matrik karakteristik lapis jamak pada perumusan nilai eigen persamaan directional-coupler linier diawali dengan proses reduksi dimensi penampang transversal pandu gelombangnya, dari dimensi dua ke dimensi satu. Reduksi dimensi tersebut lazim dilakukan dengan metode indeks efektif. Melalui penerapan metode indeks efektif ini, struktur directional-coupler cukup ditinjau dalam arah lateralnya, yang dalam hal ini membentuk struktur pandu gelombang berlapis jamak berisi lima buah lapisan tipis. Kedua pandu gelombang beserta daerah gapnya berfungsi sebagai stack pemandu gelombang, sedangkan dua lapisan lainnya masing-masing berfungsi sebagai substrat dan kover sebagaimana pada pandu gelombang papak (slab-waveguides). Karena itu secara prinsip penurunan persamaan nilai eigen Helmholtznya dapat dilakukan menggunakan kaidah yang berlaku pada pandu gelombang papak [8, 20, 21].

Pengembangan metode matrik karakteristik pandu gelombang berlapis jamak didasarkan pada kontinuitas komponenkomponen medan cahaya terpandu pada setiap perbatasan antar lapisannya. Penerapan syarat kontinuitas dimaksud dilakukan mengacu pada Gambar 2.

Sebagaimana tampak pada Gambar 2, pandu gelombang berlapis jamak berupa sebuah stack berisi $\mathrm{N}$ buah lapisan yang tersisip diantara substrat dan kover. Penerapan syarat kontinuitas semua komponen medan cahaya pada setiap perbatasan lapisan di daerah stack dilakukan untuk menjamin keutuhan setiap komponen medan terpandu sebagimana pada daerah film pandu gelombang papak. Sedangkan kontinuitas komponen medan di perbatasan stack-substrat dan di perbatasan stack-kover dilakukan untuk menjamin keutuhan komponen medan terpandu dengan komponen medan yang ter-evanescent ke daerah substrat dan kover. Untuk setiap modus cahaya, Kogelnik[8], Emmanuel dkk[9], Uranus dkk[20], Rohedi dkk[21], menerapkan kontinuitas komponenkomponen medan tangensial dan menuliskanya secara kesatuan dalam sebuah vektor kolom. Untuk modus TE yaitu cahaya terpandu dengan medan listrik tegak lurus bidang datang, komponen medan tangensialnya adalah komponen listrik dan komponen medan magnet $H_{z}\left(\approx \partial E_{y} / \partial x\right)$. Penerapan syarat kontinuitas tersebut dilakukan dengan memanfaatkan medan

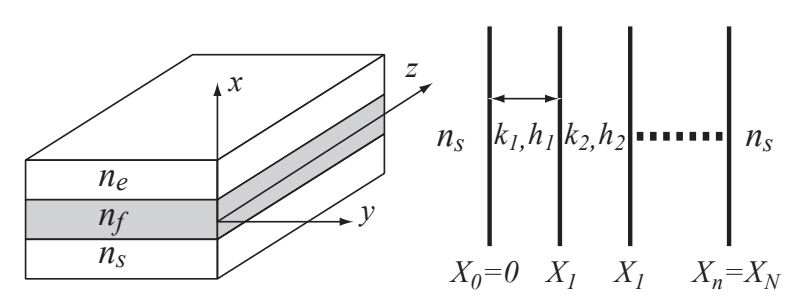

Gambar 2: (a) Struktur pandu gelombang Papak, (b) Struktur pandu gelombang berlapis jamak 
listrik solusi umum persamaan Helmholtz untuk modus TE yang berbentuk $E_{y}=A \cos \kappa x+B \sin \kappa x$, dengan nilainilai faktor tetapan propagasi, tetapan A dan B adalah spesifik untuk setiap lapisan. Dari penerapan syarat kontinuitas tersebut, hubungan komponen medan tangensial antar dua perbatasan terdekat di daerah stack didapatkan dalam bentuk matrik berordo $2 \times 2$, yaitu :

$$
M_{j}=\left[\begin{array}{cc}
\cos \kappa_{i} h_{i} & \frac{j}{\kappa_{i}} \sin \kappa_{i} h_{i} \\
j \kappa_{i} \sin \kappa_{i} h_{i} & \cos \kappa_{i} h_{i}
\end{array}\right]
$$

dengan $i=1,2,3, \cdots, N, j=\sqrt{-1}, \kappa_{i}=\sqrt{k_{0}^{2} n_{i}^{2}-\beta^{2}}$ $n_{i}$ adalah indeks bias setiap lapisan bahan, $k_{0}=2 \pi / \lambda$ adalah bilangan gelombang dalam ruang hampa, $\lambda$ adalah panjang gelombang optik, dan $\beta$ adalah tetapan tetapan propagasi efektif moda cahaya terpandu. Maktrik dalam Pers.(1) dinamakan matrik karakteristik lapisan, yang berlaku untuk setiap lapisan di daerah Stack. Lebih lanjut didapatkan pula bahwa hubungan antar komponen medan tangensial di perbatasan stack-substrat dengan di perbatasan stack-kover juga dalam bentuk matrik berordo $2 \times 2$, yang didapatkan dari hasil perkalian semua matrik karakteristik lapisan-lapisannya,

$$
\left[\begin{array}{c}
E_{y s} \\
\frac{\partial E_{y s}}{\partial x}
\end{array}\right]=m\left[\begin{array}{c}
E_{y c} \\
\frac{\partial E_{y c}}{\partial x}
\end{array}\right]
$$

dengan

$$
m=\left[\begin{array}{ll}
m_{11} & m_{12} \\
m_{21} & m_{22}
\end{array}\right]=M_{1} M_{2} c M_{n-1} M_{n}
$$

dengan s dan c menyatakan substrat dan kover. Adapun persamaan nilai eigen persamaan Helmholtz untuk pandu gelombang berlapis jamak didapatkan dalam bentuk[8, 9, 20, 21]:

$$
j\left(m_{11} \gamma_{s}+m_{22} \gamma_{c}\right)+\gamma_{s} \gamma_{c} m_{12}-m_{21}=0
$$

dengan $\gamma_{s}=\sqrt{\beta^{2}-\left(k_{0} n_{s}\right)^{2}}$ dan $\gamma_{c}=\sqrt{\beta^{2}-\left(k_{0} n_{c}\right)^{2}}$, masing-masing adalah tetapan propagasi dari komponen medan yang ter-evanescent ke daerah substrat dan kover, sedangkan $n_{s}$ dan $n_{c}$ berturut-turut adalah indeks bias substrat dan kover. Persamaan (4) di atas didapatkan dari penerapan syarat kontinuitas komponen medan tangensial pada perbatasan stack-substrat dan perbatasan stack-kover dalam Pers.(2) dengan komponen medan tangensial yang terevanescent ke daerah substrat dan kover.

\section{FORMULASI TETAPAN PROPAGASI EFEKTIF}

Pada makalah ini, perumusan formulasi tetapan efektif cahaya modus TE untuk directional coupler linier dengan metode matrik karakteristik lapis jamak diawali dengan perumusan matrik karakteristik stack. Matrik stack dimaksud didapatkan dari perkalian matrik-matrik berikut :matrik lapisan pandu gelombang pertama dengan lebar $h_{1}$, matrik lapisan daerah gap dengan lebar $S$, dan matrik lapisan pandu gelombang kedua dengan $h_{2}$, yaitu :

$$
\begin{aligned}
m= & M_{1} M_{2} M_{3} \\
= & {\left[\begin{array}{cc}
\cos \left(\kappa_{1} h_{1}\right) & \frac{1}{\kappa_{1}} \sin \left(\kappa_{1} h_{1}\right) \\
j \kappa_{1} \sin \left(\kappa_{1} h_{1}\right) & \cos \left(\kappa_{1} h_{1}\right)
\end{array}\right] \times } \\
& {\left[\begin{array}{cc}
\cos \left(\kappa_{s} S\right) & \frac{1}{\kappa_{s}} \sin \left(\kappa_{s} S\right) \\
j \kappa_{s} \sin \left(\kappa_{s} S\right) & \cos \left(\kappa_{s} S\right)
\end{array}\right] \times } \\
& {\left[\begin{array}{cc}
\cos \left(\kappa_{2} h_{2}\right) & \frac{1}{\kappa_{2}} \sin \left(\kappa_{2} h_{2}\right) \\
j \kappa_{2} \sin \left(\kappa_{2} h_{2}\right) & \cos \left(\kappa_{2} h_{2}\right)
\end{array}\right] }
\end{aligned}
$$

dengan, $\kappa_{1}=\sqrt{k_{0}^{2} n_{1}^{2}-\beta^{2}}, \kappa_{s}=\sqrt{k_{0}^{2} n_{s}^{2}-\beta^{2}}$, dan $\kappa_{2}=$ $\sqrt{k_{0}^{2} n_{2}^{2}-\beta^{2}}$. Kemudian memasukkan ke empat elemen matrik $m$ dalam Pers.(5) ke dalam Pers.(4), hasilnya adalah

$$
\begin{aligned}
& \gamma_{s} T_{1}-\gamma_{s} \frac{\kappa_{s}}{\kappa_{1}} T_{2}-\gamma_{s} T_{3}\left(\frac{\kappa_{2}}{\kappa_{s}}+\frac{\kappa_{s}}{\kappa_{2}}\right)- \\
& \gamma_{s} T_{4}\left(\frac{\kappa_{2}}{\kappa_{1}}+\frac{\kappa_{1}}{\kappa_{2}}\right)-T_{5}\left(\kappa_{1}+\frac{\gamma_{s} \gamma_{c}}{\kappa_{1}}\right)- \\
& T_{6}\left(\kappa_{s}+\frac{\gamma_{s} \gamma_{c}}{\kappa_{s}}\right)-T_{7}\left(\kappa_{s} \frac{\gamma_{s} \gamma_{c}}{\kappa_{1} \kappa_{2}}-\frac{\kappa_{1} \kappa_{2}}{\kappa_{s}}\right)- \\
& T_{8}\left(\kappa_{2}-\frac{\gamma_{s} \gamma_{c}}{\kappa_{2}}\right)=0,
\end{aligned}
$$

dengan

$$
\begin{aligned}
& T_{1} \equiv \cos \left(\kappa_{1} h_{1}\right) \cos \left(\kappa_{s} S\right) \cos \left(\kappa_{2} h_{2}\right), \\
& T_{2} \equiv \sin \left(\kappa_{1} h_{1}\right) \sin \left(\kappa_{s} S\right) \cos \left(\kappa_{2} h_{2}\right), \\
& T_{3} \equiv \cos \left(\kappa_{1} h_{1}\right) \sin \left(\kappa_{s} S\right) \sin \left(\kappa_{2} h_{2}\right), \\
& T_{4} \equiv \sin \left(\kappa_{1} h_{1}\right) \cos \left(\kappa_{s} S\right) \sin \left(\kappa_{2} h_{2}\right), \\
& T_{5} \equiv \sin \left(\kappa_{1} h_{1}\right) \cos \left(\kappa_{s} S\right) \cos \left(\kappa_{2} h_{2}\right), \\
& T_{6} \equiv \cos \left(\kappa_{1} h_{1}\right) \sin \left(\kappa_{s} S\right) \cos \left(\kappa_{2} h_{2}\right), \\
& T_{7} \equiv \sin \left(\kappa_{1} h_{1}\right) \sin \left(\kappa_{s} S\right) \sin \left(\kappa_{2} h_{2}\right), \\
& T_{8} \equiv \cos \left(\kappa_{1} h_{1}\right) \cos \left(\kappa_{s} S\right) \sin \left(\kappa_{2} h_{2}\right) .
\end{aligned}
$$

Penyederhanan persamaan nilai eigen dalam Pers.(6) dilakukan dengan memanfaatkan definisi faktor pergeseran fasa pantulan[8, 21] pada perbatasan substrat $\phi_{s}=\arctan \left(\gamma_{s} / \kappa_{1}\right)$, dan pada perbatasan kover $\phi_{c}=\arctan \left(\gamma_{c} / \kappa_{2}\right)$, hasilnya adalah

$$
\frac{\kappa_{2}}{\kappa_{s}} T_{22}=-\frac{\frac{\kappa_{1}}{\kappa_{s}} T_{11}+\tan \left(\kappa_{s} S\right)}{1-\frac{\kappa_{1}}{\kappa_{s}} T_{11}+\tan \left(\kappa_{s} S\right)}
$$

dengan,

$$
\begin{aligned}
& T_{11} \equiv \tan \left(\kappa_{1} h_{1}-\phi_{s}\right) \\
& T_{22} \equiv \tan \left(\kappa_{2} h_{2}-\phi_{c}\right)
\end{aligned}
$$

Selanjutnya dengan mendefinisikan

$$
\tan \left(\phi_{1 s}\right)=\frac{\kappa_{1}}{\kappa_{s}} T_{11}
$$


TABEL I: Nilai tetapan propagasi efektif medan moda simetri directional-coupler linier struktur simetri

\begin{tabular}{ccccccccc}
\hline \hline $\mathrm{S}$ & \multicolumn{3}{c}{ Persamaan eigen (4) } & \multicolumn{3}{c}{ Analitis Pers.(9) } & \multicolumn{3}{c}{ Kogelnik Pers.(11) } \\
$(\mu \mathrm{m})$ & $N_{0}$ & $N_{1}$ & $\beta(1 / \mu \mathrm{m})$ & $N_{0}$ & $N_{1}$ & $\beta(1 / \mu \mathrm{m})$ & $N_{0}$ & $N_{1}$ \\
\hline 0 & 2,148 & 2,149 & 10,1474 & 2,148 & 2,149 & 10,1474 & 2,148 & 2,149 \\
0,5 & 2,148 & 2,149 & 10,1434 & 2,148 & 2,149 & 10,1434 & 2,148 & 2,149 \\
1 & 2,148 & 2,149 & 10,1409 & 2,148 & 2,149 & 10,1409 & 2,148 & 2,149 \\
2 & 2,148 & 2,149 & 10,1381 & 2,148 & 2,149 & 10,1381 & 2,145 & 2,146 \\
3 & 2,148 & 2,149 & 10,1368 & 2,148 & 2,149 & 10,1368 & 2,145 & 2,146 \\
4 & 2,148 & 2,149 & 10,1361 & 2,148 & 2,149 & 10,1361 & 2,145 & 2,146 \\
\hline \hline
\end{tabular}

TABEL II: Nilai tetapan propagasi efektif medan moda asimetri textitdirectional-coupler struktur simetri

\begin{tabular}{ccccccccc}
\hline \hline $\mathrm{S}$ & \multicolumn{3}{c}{ Persamaan eigen (4) } & \multicolumn{3}{c}{ Analitis Pers.(9) } & \multicolumn{3}{c}{ Kogelnik Pers.(11) } \\
$(\mu \mathrm{m})$ & $N_{0}$ & $N_{1}$ & $\beta(1 / \mu \mathrm{m})$ & $N_{0}$ & $N_{1}$ & $\beta(1 / \mu \mathrm{m})$ & $N_{0}$ & $N_{1}$ \\
\hline 0 & 2,141 & 2,142 & 10.1221 & 2,141 & 2,142 & 10,1221 & 2,141 & 2,142 \\
0,5 & 2,141 & 2,142 & 10.1257 & 2,141 & 2,142 & 10,1257 & 2,141 & 2,142 \\
1 & 2,142 & 2,143 & 10.1286 & 2,142 & 2,143 & 10,1286 & 2,142 & 2,143 \\
2 & 2,143 & 2,144 & 10.1322 & 2,143 & 2,144 & 10,1322 & 2,143 & 2,144 \\
3 & 2,143 & 2,144 & 10.1339 & 2,143 & 2,144 & 10,1339 & 2,144 & 2,145 \\
4 & 2,143 & 2,144 & 0.1347 & 2,143 & 2,144 & 0,1347 & 2,144 & 2,145 \\
\hline \hline
\end{tabular}

dengan $\phi_{1 s}$ adalah faktor pergeseran fasa pantulan pada perbatasan pandu gelombang pertama dan daerah gap, maka Pers.(8) tereduksi ke dalam bentuk :

$$
\kappa_{2} \tan \left(\kappa_{2} h_{2}-\phi_{s}\right)=-\kappa_{s} \tan \left(\kappa_{s} S+\phi_{1 s}\right)
$$

Persamaan nilai eigen dalam Pers.(9) berlaku untuk semua ragam moda (orde genap dan ganjil), serta berlaku untuk struktur directional coupler simetri atau asimetri. Perumusan matrik stack di atas berbeda dengan yang dilakukan oleh Kogelnik[8], yang menetapkan pusat (center) lebar gap directional-coupler sebagai pusat koordinat. Matrik stack untuk directional coupler simetri didapatkan dari $m=$ $M_{1} M_{s} M_{s} M_{1}$, dengan $M_{1}$ sama seperti pada Pers.(5), sedangkan $M_{s}$ adalah:

$$
M_{s}=\left(\begin{array}{cc}
\cos \left(\frac{\kappa_{s} S}{2}\right) & \frac{j}{\kappa_{s}} \sin \left(\frac{\kappa_{s} S}{2}\right) \\
j \kappa_{s} \sin \left(\frac{\kappa_{s} S}{2}\right) & \cos \left(\frac{\kappa_{s} S}{2}\right)
\end{array}\right)
$$

Dan setelah memasukkan elemen $m$ ke dalam Pers.(4) dihasilkan dua buah persamaan nilai eigen, yang masing-masing berlaku untuk moda genap dan moda ganjil. Persamaan nilai eigen untuk moda genap berbentuk

$$
\kappa_{s} \tan \left(\frac{\kappa_{s} S}{2}\right)=-\kappa \tan \left(\kappa_{1} h_{1}-\phi\right)
$$

sedangkan untuk moda ganjil berbentuk

$$
\kappa_{s} \tan \left(\frac{\kappa_{s} S}{2}\right)=\kappa \tan \left(\kappa_{1} h_{1}-\phi\right)
$$

pada kedua persamaan nilai eigen tersebut terdefinisi $\phi=$ $\arctan \left(\frac{\kappa_{s}}{\kappa_{1}}\right)$.

\section{HASIL PERHITUNGAN DAN DISKUSI}

Bila ditinjau dari bentuk persamaannya, Pers.(9), Pers. (11), dan Pers.(12) adalah berbentuk persamaan nonlinier, sehingga nilai eigen tetapan propagasi efektifnya $(\beta)$ hanya dapat ditentukan dengan metode numerik. Salah satu metode numerik yang lazim digunakan adalah metode secant[22]. Untuk memudahkan pemberian dua nilai tebakan awal yang diperlukan pada penerapan metode secant, maka $\beta$ diganti dengan nilai indeks bias efektif $N$ sesuai definisi $\beta=k_{0} N$, sehingga penyelesaian persamaan nonlinier tesebut berganti untuk menentukan nilai $N$. Untuk menghindari ketakkonvergenan penyelesaiannya, maka dua tebakan awal untuk $N$ yang diberikan, harus mematuhi kriteria pemanduan gelombang, yaitu dalam rentang $n_{s}<\left(N_{0}\right.$ dan $\left.N_{1}\right)<n_{1}, n_{2}$. Perlu diperhatikan, bahwa nilai indeks bias pandu gelombang $n_{1}$ dan $n_{2}$ adalah nilai indeks bias efektif arah kedalamannya, sebagaimana yang dipersyaratkan oleh metode indeks efektif. Nilai indeks bias efektif arah kedalaman ini seharusnya ditentukan melalui penyelesaian persamaan eigen pandu gelombang papak (moda dasar) yang merupakan struktur arah kedalaman directional coupler[8,21], yaitu :

$$
\begin{aligned}
& \frac{2 \pi}{\lambda} d \sqrt{n_{f}^{2}-N_{d}^{2}}-\arctan \left(\sqrt{\frac{N_{d}^{2}-n_{s}^{2}}{n_{f}^{2}-N_{d}^{2}}}\right) \\
&-\arctan \left(\sqrt{\frac{N_{d}^{2}-n_{s}^{2}}{n_{f}^{2}-N_{d}^{2}}}\right)=0
\end{aligned}
$$

dengan d adalah tebal pandu gelombang, dan $n_{c}=1$ karena kovernya berupa udara. Tetapi untuk mempersingkat perhitungan, maka pada makalah ini nilai $N_{d}$ tersebut ditetapkan. Penyelesaian persamaan nilai eigen dalam Pers.(89), Pers. (11) dan Pers. (12) dilakukan untuk directional coupler simetri, dengan data sebagai berikut : panjang gelombang op- 
tik $\lambda=1,33 \mu \mathrm{m}$, indeks bias efektif arah kedalaman kedua pandu gelombang $n_{1}=n_{2}=N_{d}=2,15$, indeks bias substrat dan daerah gap $n_{s}=N_{S}=2,14$, dan lebar kedua pandu gelombang $h_{1}=h_{2}=h=1,5 \mu \mathrm{m}$. Lebar pandu gelombang yang ditetapkan ini masih mematuhi kriteria pemasokan energi cahaya moda tunggal, yaitu $h<(\lambda / 2) / \sqrt{N_{d}^{2}-n_{s}^{2}}$, sehingga cahaya yang terpandu dalam directional-coupler terdistribusi atas moda simetri dan moda asimetri. Hasil perhitungan $\beta$ moda simetri dan moda asimetri untuk lebar gap yang divariasi berturut-turut ditunjukkan dalam Tabel I dan Tabel II.

Seperti tampak pada kedua tabel di atas, hasil perhitungan nilai tetapan propagasi efektif $\beta$ medan moda simetri dan asimetri yang diperoleh dari persamaan nilai eigen yang dikembangkan penulis, identik dengan yang didapatkan Kogelnik[8]. Hasil perhitungan $\beta$ nya sama sama identik dengan yang diperoleh dari Pers.(4) yang matrik stacknya dalam Pers.(5) diperkalikan secara langsung. Namun demikian persamaan eigen directional coupler yang dikembangkan penulis lebih sederhana karena dapat berlaku untuk kedua ragam moda, tergantung pada tebakan awal yang diberikan. Dua nilai tebakan $N$ untuk moda simetri diberikan mendekati $N_{d}$, sebaliknya nilai tebakan untuk moda asimetri mendekati nilai $n_{s}$.

\section{KESIMPULAN}

Metode matrik karakteristik pandu gelombang berlapis jamak dapat menghasilkan formulasi nilai tetapan propagasi efektif moda simetri dan asimetri cahaya yang terpandu dalam directional-coupler linier dalam bentuk analitis.

Kesimetrian dari struktur directional coupler yang dgunakan dalam langkah formulasi sangat menentukan, apakah bentuk persamaan tetapan propagasi efektif tersebut berlaku hanya untuk masing-masing moda simetri dan moda asimetri, atau secara kesatuan.
[1] Ed.L.Wooten, Karl M.Kissa, Alfredo Yi-Yan,"A Review of Lithium Niobate Modulators for Fiber Optic Communication System”, IEEE Journal OF Selected Topics In Quantum Electronic, Vol 6, No.1, January/Pebruary, 2000.

[2] Alferness,R.C, ,"Guided-wave devices for optical communications", IEEE Journal Quantum Electronic, QE-17, 1981.

[3] Per Danielsen, "Two Dimensional Propagating Beam Analysis of an Electrooptic Waveguide Modulator", IEEE Journal of Quantum Electronics, Vol.QF-20,No.9 September 1984.

[4] Amalia N.Miliou, Ramakant Srivastava, and R.V.Ramasvamy: "A1,3 Directional-coupler Polarization Splitter by Ion Exchanged" , Journal of Lightwave Technology, Vol.11, No.2, February 1993.

[5] Ary Ternoven, Seppo Honkamen, S.Iraj Najafi :" Analysis of Symetrical Directional-coupler and Asymetric Mach-Zehnder Interferometer as 1,3 and 1,5 Dual Wavelength Demultiplexer /Multiplexer.

[6] Pramono H, "Studies on All-Optical Switching in Crossing Waveguides Consisting of Nonlinier Material", Dissertasion of Doctor of Engineering in Electrical and Electronic System at the Graduate School of College of Engineering, Osaka Prefecture University, Maret 2000.

[7] Harsoyono, RE Siregar, and M.O Tjia, "A Studi of Nonlinier Coupling Between Two Identical Planar Waveguide", Journal Nonlinear Optical Physics and Material. Enginering, 2001.

[8] Kogelnik, "Theory of Optical Waveguides in Guide-Wave Optoelectronics", Editor Theodor Tamir, Chapter 1, 2nd edition, springer-verlag, New York, 1990.

[9] Emmauel Anemogiannis, Elias Glytsis,"Multilayer Waveguides: Efficient Numerical Analysis of General Structures", Journal of Lightwave of Technology, Vol 10, No.10, October 1992.

[10] Herman A.Hauss, WP. Huang, "Coupled-Mode Theory", Proceeding of the IEEE, Vol 79,No.10, October 1991.

[11] W.K.Burn and A.F.Milton,[1990],'Theory of Optical Waveguides in Guide-Wave Optoelectronics", Editor Theodor Tamir, 2nd edition, springer-verlag, New York

[12] F.J.Leonberger and J.P.Donnelly,[1990],’Theory of Optical
Waveguides in Guide-Wave Optoelectronics”, Editor Theodor Tamir, 2nd edition, springer-verlag, New York

[13] Emanuel Marom et al,[1984],"Relation Between Normalmodes and Coupled-Modes Analysis of Parallel Waveguides", Journal Of Qantum Electronics, Vol.QE-20,No.11, December.

[14] K.Chiang, [1986],'Dual Effective index method the analysis of rectanguler waveguides", Applied Optic, Vol 25.

[15] Timo A. Laine, Ari T.Filberg,"Rigorous volune grating solution to distortion correction in nonliniear layered media near a phase-conjugate mirror", Elsevier Optic Communication 159, 1999.

[16] Arif Bustomi, Ali Yunus Rohedi, Mahmud Zaki,"Filter Dielektrik dengan Daerah Penolakan Lebar", Proceeding Simposium Fisika dan Aplikasinya", Jurusan Fisika FMIPA-ITS, April 2002.

[17] H. Ghafouri-Shiraz, B.S.K,Lo,'Distributed Feedback Laser Diodes", Principles and Physical Modelling John Wiley \& Sons.

[18] M.R Vladimirova, A.V. Kurokin, M.A Kaliteevski, "Dispersion of Bulk exciton in a semiconductor microcavity", Physical Review B, Vol 54, No 20, Nopember 1996.

[19] Suryadi,"Study on the Coherent Excitonic Nonlinearity in Semiconductor Quantum Wells by Four Wave Mixing Spectroscopy", Dissertasion of Doctor of Materials Engineering Graduate School of Engineering, Hiroshima University, 2002.

[20] Henry P. Uranus , John E. Batubara,'Analisis Moda pada Pandu Gelombang Optik Berlapis Jamak dengan Bantuan Matriks Karakteristik", Prosiding Simposium Himpunan Fisika Indonesia, Ikip Surabaya, 1994.

[21] A.Y. Rohedi, G. Yudoyono, Mat Nafik, "Calculating approximate for the propagation constant of Optical Waveguides Using Multilayer Characteristic Matrix”, Prosccding of Aplied Physics, Pysics Departement, Sepuluh Nopember Institute of Technology, April, 2002.

[22] Nakamura, [1990],"Applied Numerical Methods With Software", Prentice Hall. 